Volume 9, No.1, January - February 2020

International Journal of Advanced Trends in Computer Science and Engineering

Available Online at http://www.warse.org/IJATCSE/static/pdf/file/ijatcse92912020.pdf

https://doi.org/10.30534/ijatcse/2020/92912020

\title{
Semantic Web Services Discovery Approach Based on MARDS
}

\author{
Mohamed HALIM ${ }^{1}$, Nouha ADADI ${ }^{2}$, Driss CHENOUNI ${ }^{3}$, Mohammed BERRADA ${ }^{4}$ \\ ${ }^{1}$ IPI Laboratory, Sidi Mohamed Ben Abdellah University -Fez, Morocoo, mohamed.halim@usmba.ac.ma \\ ${ }^{2}$ IPI Laboratory, Sidi Mohamed Ben Abdellah University -Fez, Morocoo, nouhaadadi@gmail.com \\ ${ }^{3}$ IPI Laboratory, Sidi Mohamed Ben Abdellah University -Fez, Morocoo, Morocoo, d_chenouni@yahoo.fr \\ ${ }^{4}$ IASSE Laboratory, Sidi Mohamed Ben Abdellah University -Fez, Morocoo, Morocoo, mohammed.berrada@gmail.com
}

\begin{abstract}
Web services are a way for businesses to offer their services over the Web. The concept of semantic Web services, is the fruit of the convergence of Web services field with the Semantic Web, indeed its main objective is to make web services more accessible to the machine by automating the various tasks of their life cycle such as discovery, selection, invocation and composition. In this work, we study the problem of semantic discovery of services by exposing a state of the art on the discovery approaches achieved, and proposing a method that is based on Multi-Agent Reactive Decisional Systems (MARDS) and ontologies. The use of a multi-agent system ensures great flexibility in our proposed approach.
\end{abstract}

Key words: semantic Web services; discovery of services; Multi-Agent Reactive Decisional Systems; ontologies.

\section{INTRODUCTION}

Since the early 2000s, many research axis concerning the Internet have turned to the semantic Web. The Internet is a huge reservoir of documents of all kinds (articles, personal sites, audios, videos), but the more these resources accumulate, the harder it is to find accurate information. Tim Berners-Lee [1] suggests adding to all of these resources a semantic, which allows computer systems to understand their meaning by accessing to structured collections of information and inference rules, which can be used to conduct automated reasoning: this is the birth of the Semantic Web.

The Web is no longer just a huge warehouse of text and images, its evolution has made it also a service provider. The concept of "Web service" essentially designates an application made available on the Internet by a service provider, and accessible by customers through standard protocols: WSDL [2], UDDI [3] and SOAP [4]. These technologies facilitate description, discovery and communication between services. However, this basic infrastructure does not allow automated management of web services. This automation is essential for scaling up (handling a large number of web services) and reducing the costs of development of services. For this reason, this automation must accommodate a way to describe web services in a manner understandable by a machine: This is the birth of semantic web services.

Our work is to propose an approach that combines the Multi agent system (MAS) with ontology in order to reduce time and development costs, while making the discovery of Web services more reliable.

The layout of this paper is as follows. The second section presents an overview of web services discovery approaches as well as a summary of the Multi Agent Reactive Decisional System (MARDS). The third section is devoted to the presentation of the proposed approach. As part of a case study we consider an online travel organization problem in the fourth section. This problem is a typical web services discovery scenario to apply the concepts of our approach. The fifth section is devoted to conclusion and future work.

\section{LITERATURE REVIEW}

\subsection{Semantic Web Services}

Semantic Web services are Web services described in such a way that a machine (computer, software, etc.) can interpret the functionalities offered by these services. A software agent must be able to read the description of a web service to determine if the web service provides the desired functionality. To allow this, the description of the Web service must be supplemented with semantic information interpretable by machine. The parameters of the Web service must be described in such a way that a software agent can know their meaning. This is done by defining vocabularies organized into ontologies [5].

In the field of Web services, ontologies are used to annotate descriptions of the functionality of semantic Web services. Thus, for a software agent to have knowledge of semantics of a Web service description, it just needs to access an ontology of the domain.

The semantic web services description language is the OWL$S$ language [6], this description allows the service to have an interpretable interface, facilitating the automation of certain tasks such as discovery, selection, invocation and composition. Web service discovery presents an emerging line of research. Various approaches have been proposed in the literature [7]. The common objective of these approaches 
was to discover Web services describing certain functional criteria.

\subsection{Discovery Approachs}

With the growing number of web service providers in the Web, it is necessary to have mechanisms for the discovery of web services in an efficient and flexible manner. Web services discovery involves locating web services that describe certain functional criteria.

Initially, descriptions of web services were only made syntactically, the discovery of web services was based on techniques from the field of information retrieval. However, with the development of semantic web technologies and in order to automate the discovery of web services, new approaches based on the semantics of service descriptions have been proposed.

In general, discovery approaches depend on the level of representation, semantic or syntactic, of descriptions of Web services. However, approaches vary depending on the centralized or distributed architecture adopted. Table 1 represents a synthesis of the main approaches (syntactic and semantic) studied.

Table 1: Synthesis of discovery approaches

\begin{tabular}{|c|c|c|c|c|}
\hline & AASDU & OWL-S & SPEED-R & PSWSD \\
\hline $\begin{array}{l}\text { Description } \\
\text { of services }\end{array}$ & WSDL & $\begin{array}{l}\text { OWL } \\
\text { Ontolog } \\
\text { y for } \\
\text { Service }\end{array}$ & $\begin{array}{c}\text { Mapping } \\
\text { between } \\
\text { WSDL and } \\
\text { domain } \\
\text { ontology }\end{array}$ & $\begin{array}{c}\text { WSMO + } \\
\text { WSDL } \\
\text { Ontology }\end{array}$ \\
\hline $\begin{array}{l}\text { Architecture } \\
\text { adopted }\end{array}$ & $\begin{array}{l}\text { distribut } \\
\text { ed }\end{array}$ & $\begin{array}{c}\text { centraliz } \\
\text { ed }\end{array}$ & distributed & centralized \\
\hline $\begin{array}{l}\text { Discovery } \\
\text { technique }\end{array}$ & TFIDF & $\begin{array}{l}\text { Matchm } \\
\text { aking } \\
\text { algorith } \\
\text { m }\end{array}$ & $\begin{array}{l}\text { Keywords } \\
\text { / semantics }\end{array}$ & $\begin{array}{c}\text { Matchmak } \\
\text { er }\end{array}$ \\
\hline $\begin{array}{l}\text { Technology } \\
\text { adopted }\end{array}$ & $\begin{array}{l}\text { Multi- } \\
\text { Agents }\end{array}$ & SOAP & $\begin{array}{l}\text { Multi- } \\
\text { Agents } \\
\text { sub- } \\
\text { network } \\
\text { P2P }\end{array}$ & $\begin{array}{c}\text { Multi- } \\
\text { Agents } \\
\text { sub- } \\
\text { network } \\
\text { P2P }\end{array}$ \\
\hline
\end{tabular}

In Table 1, we can notice that when the architecture is distributed, the proposed approaches are implemented using multi-agent technology. This is well justified since this technology is well suited to the distributed nature of the problem. We also note that the semantic approaches proposed, such as OWL-S [6], Speed-R [8] and PSWSD [9], are all based on the same technique which consists in calculating the level of semantic correspondence between the functional parameters of the services and those mentioned in the search query. The difference between these approaches is the ontology language chosen, for example in PSWSD a WSMO ontology is adopted, while in OWL-S an OWL for service ontology is used. Of these ontologies, the OWL-S ontology is one that is about to become a standard.

\subsection{Multi-Agent Systems}

Multi-agent systems (MAS) offer a new approach for the development of systems with several autonomous components capable of cooperating with each other. Drawing its foundations in many disciplines, this area of research is extremely rich. This richness induces a great multiplicity of the proposed approaches which leads to very many models of MAS.

The Multi-Agent Reactive Decisional System (MARDS) [10] constitutes one of the newest and more useful models for the modeling of reactive systems. It is composed by Decisional Reactive Agents (DRA), which are linked together by communication interfaces. A DRA can be used to define an autonomous and independent agent. The agent obtained receives actions (or goals) and can act autonomously until their achievement within the appropriate time. To achieve a given goal, we can define an objective or a series of objectives chained in a certain way that we can solve this goal.

The internal structure of a MARDS is based on a two-level tree (Figure 1), composed in parallel of a Supervisor DRA (DRAS), two or more possible sub-agents, which can be in turn MARDS and interfaces communication between the supervisor and his sub-agents. For a MARDSj, it can be either a simple DRA or a MARDS built recursively.

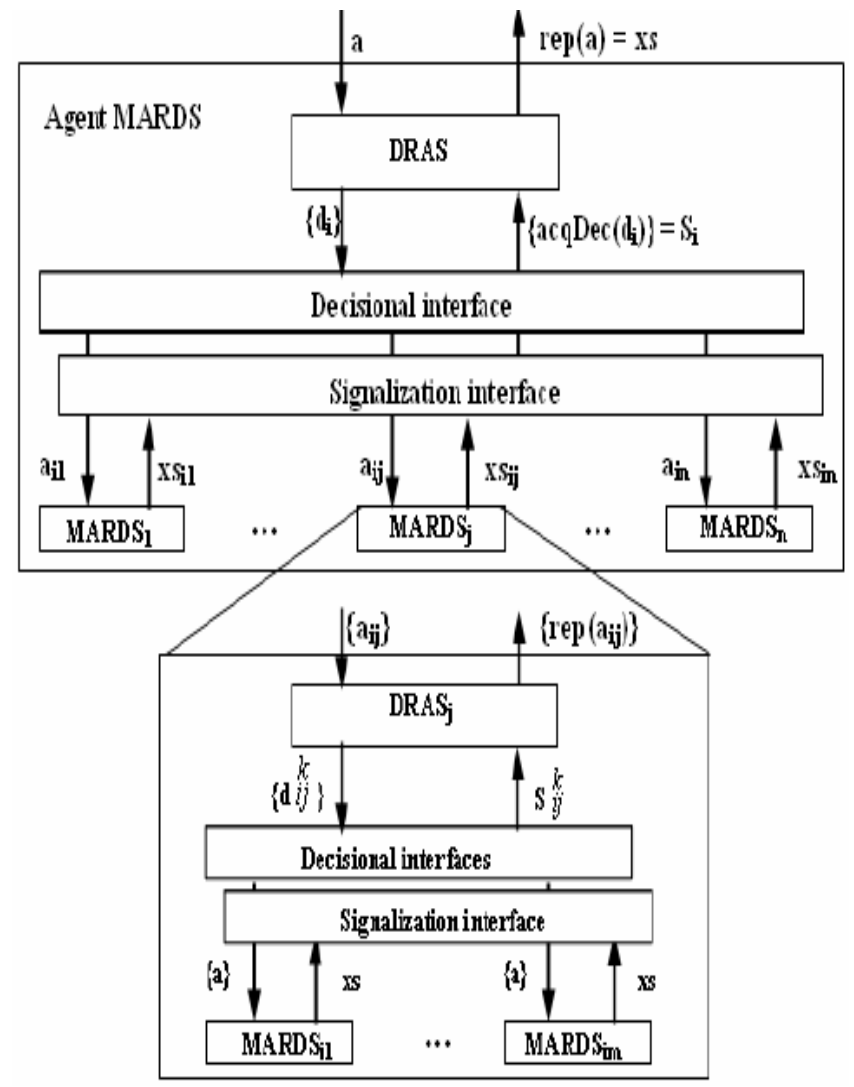

rıgure 1: Internál structurę or a IVIAKUs.

The MARDS model has been applied in the modeling and verification of automated production systems [11], the field of mobile systems [12], as well as in the modeling and implementation of composition of web services [13] [14]. 
This work proposes the use of this model for the dynamic discovery of web services.

\section{PROPOSED APPROACH}

In this section, we present an architecture (shown in Figure 2) for the discovery of semantic Web services using ontologies and agents.
The proposed approach is based on the cooperation of a set of agents structured in MARDS model, this multi-agent system which is described semantically via the ServiceProfile class of the OWL-S ontology, allows to refine the discovery process by implementing filtering mechanisms (comparison) between demand and service offers.

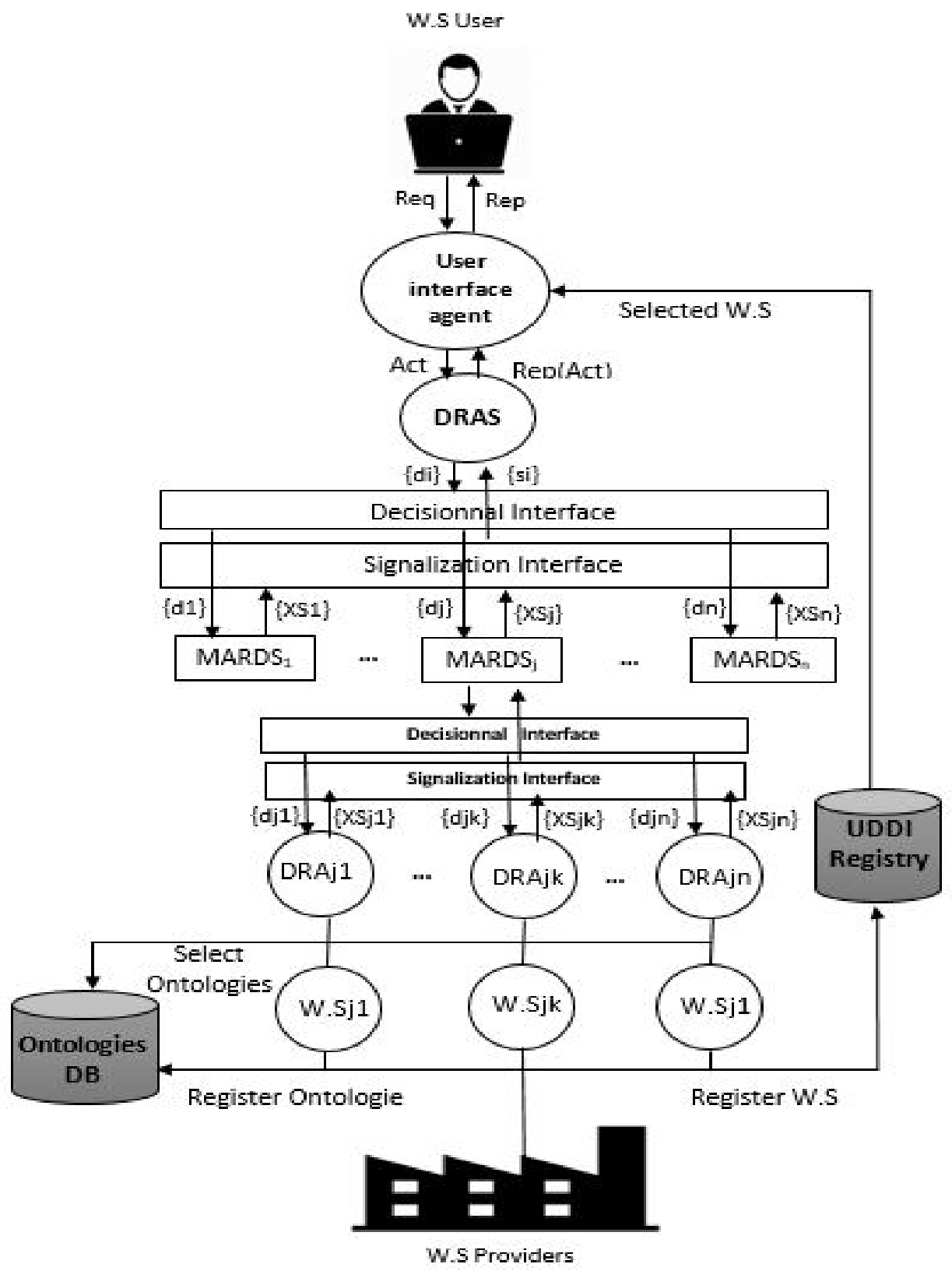

Figure 2: Proposed architecture of Web services discovery approach based on MARDS

\subsection{Architecture Description}

\section{A. User interface agent}

The user interface agent is the gateway of external requests to the system. It receives the request from the user and transfers it to the discovery agent in the form of an action with input-output parameters. The reverse operation is also available, i.e. the agent receives the results from the discovered agent and then selects the relevant services from UDDI to present them to the user.

\section{B. DRAS}

It is an agent that allows the discovery of descriptions of Web services satisfying the request sent by the user on the semantic level. 
As it is the MARDS architecture supervisor, it has the role of generating several decisions $\{\mathrm{di}, \mathrm{i}=1 \ldots \mathrm{m}\}$ on receipt of the initial action $\{a\}$. Each of these decisions will be translated by the decision interface to one or more actions $\{$ aik, $\mathrm{k}=1 \ldots$ n\} appropriate to the lower level agents $\left\{\mathrm{MARDS}_{\mathrm{k}}\right\}$. The external states issued by these agents will be translated by the signaling interface to a single signaling $\{\mathrm{si}\}$, which represents the acquittal of the decision \{di\}. The MARDS agents will subsequently generate the decision $\{\mathrm{di}+1\}$ or just the final external state $\{\mathrm{e}\}$ considered by the MARDS agent as a response to the initial action. This response returned to the supervisor contains the description of the list of relevant services which respond to the user's request.

\section{Decisional Reactive Agent (DRA)}

Each DRA agent is linked to a Web service, registered by the provider in the UDDI directory and possessing a domain ontology in the ontology database. The DRA has the role of deciding whether the service linked with it can respond to the user's request or not. To make this decision first, the DRA receives the sub-actions from his supervisor. Afterwards, it selects the corresponding domain ontology. Then, it performs the search algorithm which allows comparing the inputs and outputs of the services published in the OWL-S ontology with those defined in the request. Finally, it sends the response to the supervisor in the form of an external state $\{\mathrm{xs}\}$.

\section{Search Algorithm}

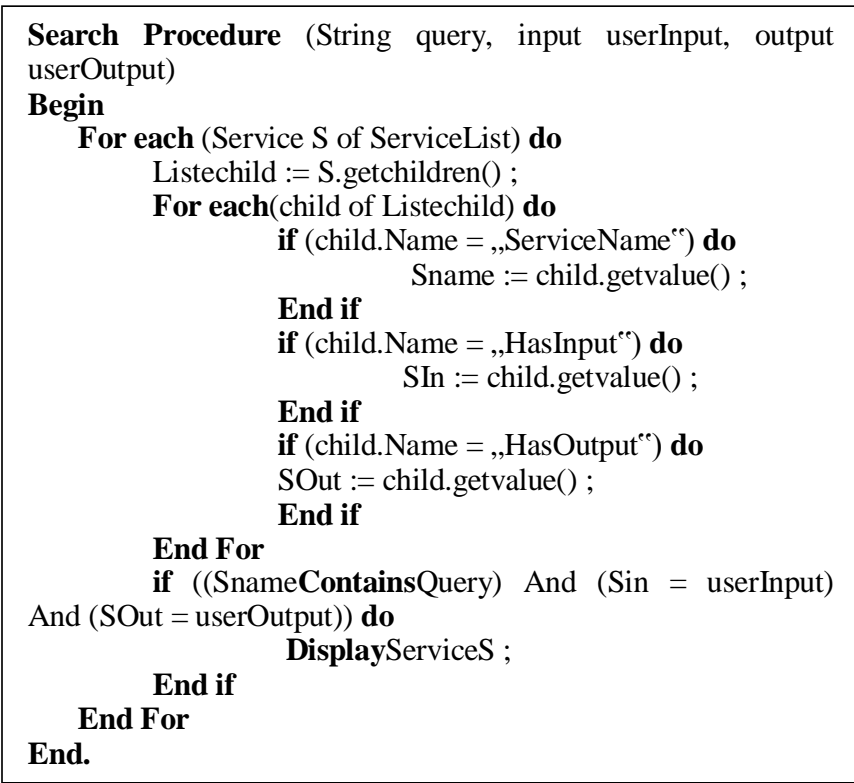

\section{E. Synthesis}

The following sequence diagram (Figure 3) summarizes the description of the architecture of the proposed discovery approach.

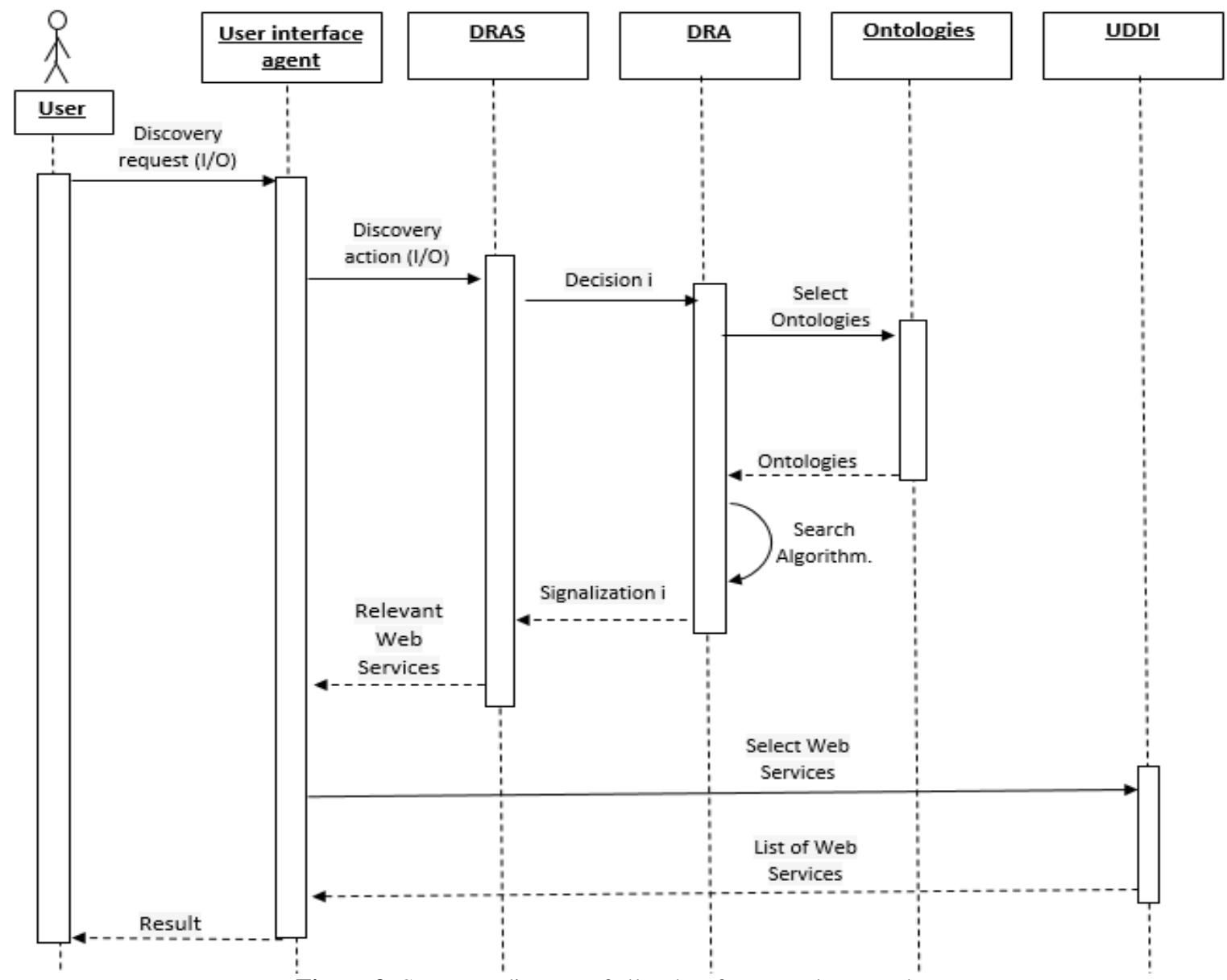

Figure 3: Sequence diagram of all tasks of proposed approach. 
- The user interface agent presents to the user of the system a form to fill in (entries, exits, etc.).

- Once the request is received, the semantic information of the request is transmitted to the DRAS in the form of an action.

- The MARDS multi-agent system transmits this action through the decisional interfaces to the basic DRA agents who process the OWL-S ontologies of the services linked with them by application of the search algorithm.

- The result is a set of relevant Web services according to the degree of semantic correspondence satisfying the user's request.

- The result is sent to the user interface agent through the MARDS system.

- The user interface agent presents the result to the user.

- And finally the user can invoke the interesting Web service (s).

\section{USE CASE}

As an illustrative example, we will consider in this work an online Travel Organization problem. This scenario is a typical web services discovery problem. As far as creating the "Travel Organization" service, we can use five basic services ("Flight", "Car Rental", "Hotel" and "Payment") that will internally execute the online Travel Organization, each one executes a task.

\subsection{Modeling of "Travel Organization" MARDS System}

The application of the concepts of MARDS model on our example allows to have the following structure (Figure 4) of the composition system by creating communication interfaces and new intermediate and main services.

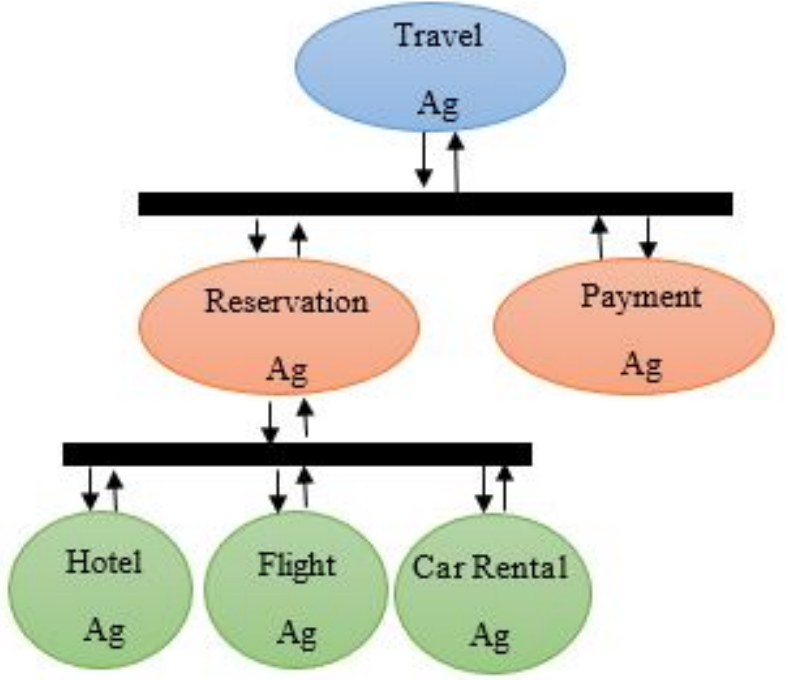

Figure 4: Structure of Travel Organization MARDS Model

We consider a user who wants to organize his travel online, he enters a request. To seek the adequate service with his request, the semantic information of the request is transmitted to the DRAS (Travel Agent) in the form of an action. The MARDS multi-agent system transmits this action through the decisional interfaces to the basic DRA agents ("Hotel Ag"; "Flight Ag"; "Car Rental Ag" and "Payment $\mathrm{Ag}$ ") who treat the OWL-S ontologies of the services linked with them by application of the search algorithm. The result is a set of relevant Web services according to the degree of semantic correspondence satisfying the user's request.

\subsection{OWL-S Ontologies of the basic services}

\section{A. Hotel Service}

This service (Figure 5) searches all the hotels located in a given city, it has as input the city and the number of rooms and the date. As output, it has all the details on the hotels of this city.

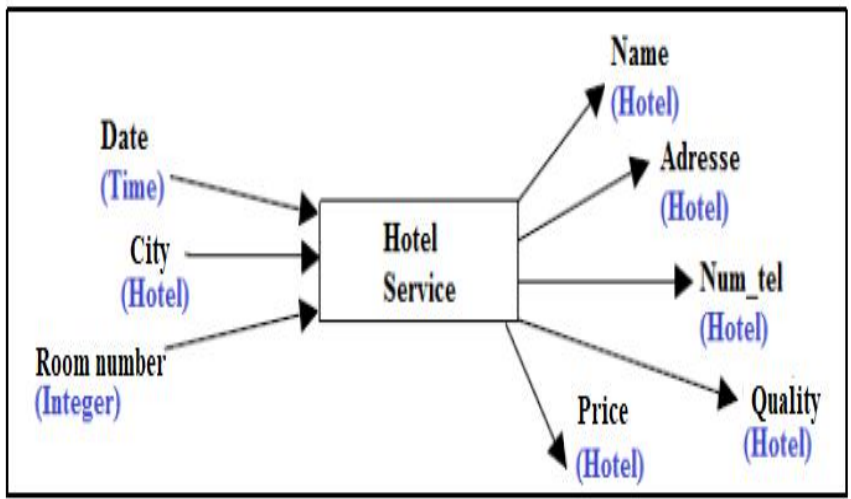

Figure 5: Hotel Service

The hierarchy of the Hotel ontology is presented in the following figure (Figure 6):

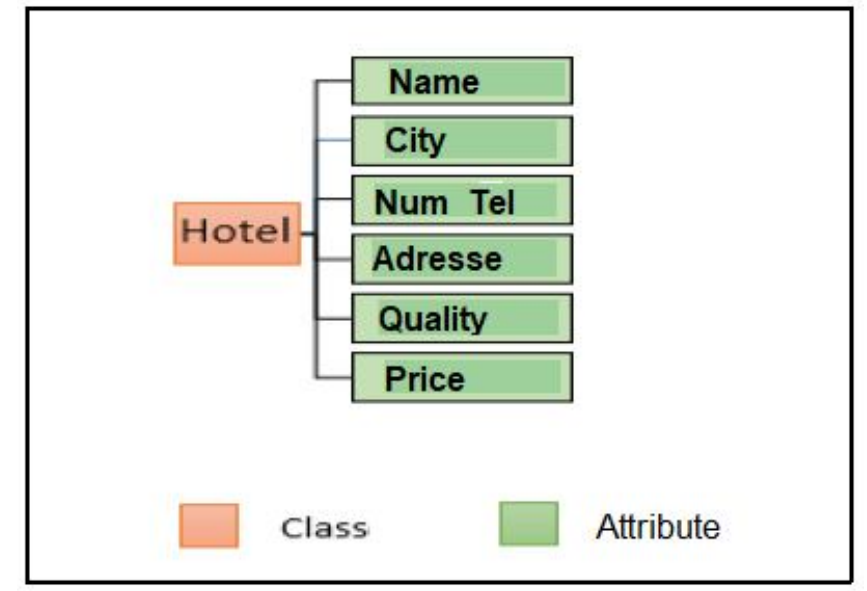

Figure 6: the Hotel ontology hierarchy

\section{B. Flight Service}

In this service (Figure 7) the user can make a reservation by entering (Departure city, Arrival city, Date and Time) to get all the flight details (price, number of passengers), the following figure represents the Flight Service: 


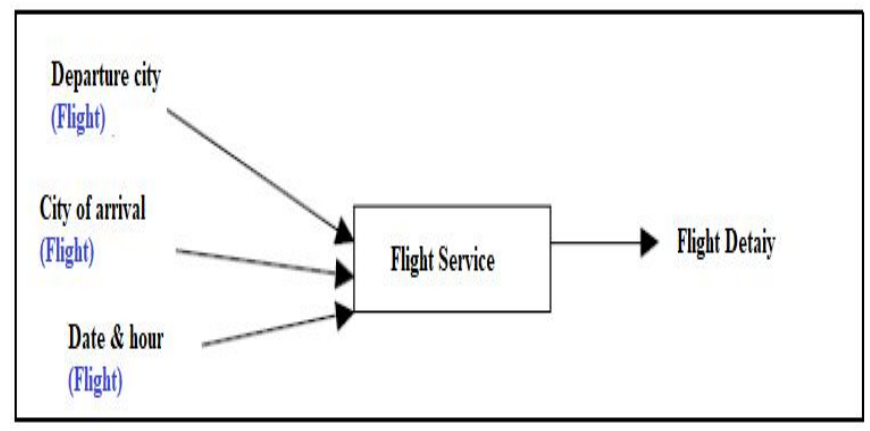

Figure 7: Flight Service

The hierarchy of the Flight ontology is presented in the following figure (Figure 8):

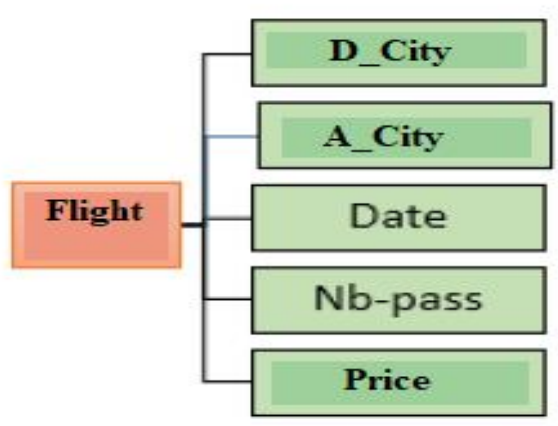

Class

Attribute

Figure 8: the Flight ontology hierarchy

\section{Car Rental Service}

The Car Rental Service (Figure 9) allows you to search for the different rental agencies that exist in a given city so the city is the entrance and we will have as exit (Name _agency, Address, Num_Tel, Car Layout, and Price).

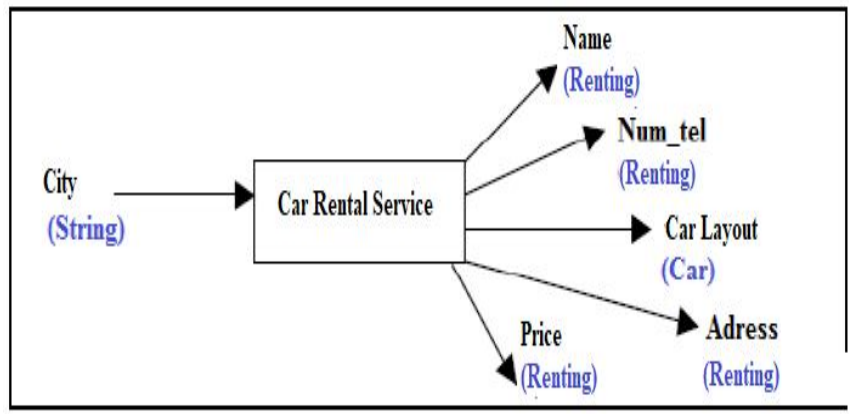

Figure 9: Car Rental Service

The following figure (Figure 10) shows the hierarchy of the Car Rental ontology:

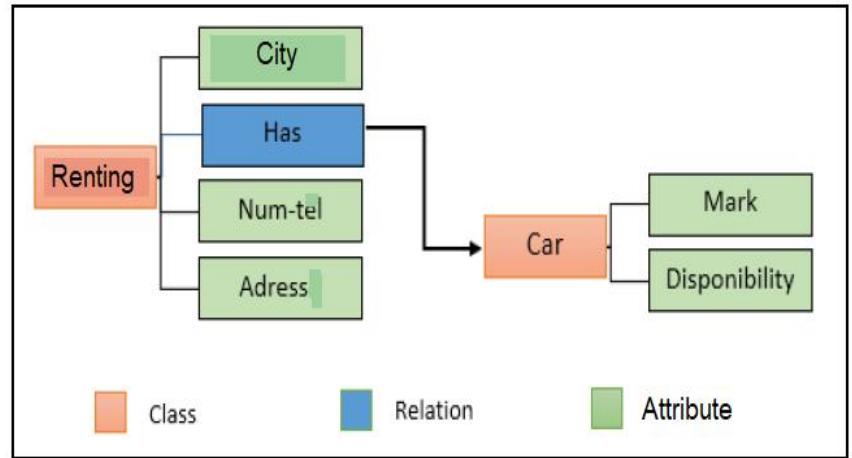

Figure 10: the Car Rental ontology hierarchy

\section{Payment service}

This service (Figure 11) allows the user to make online payment, just enter (Last name, First name, Credit_Card_Number, Price), and we will have as results a confirmation of payment.

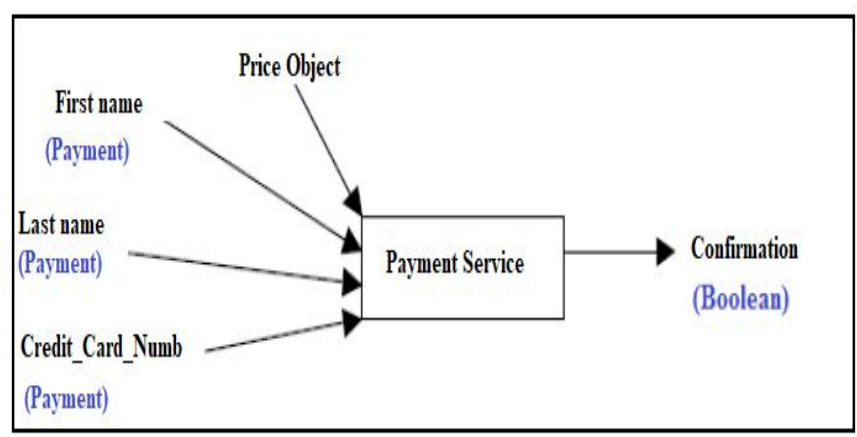

Figure 11: Payment Service

The following figure (Figure 12) shows the hierarchy of the car rental ontology:

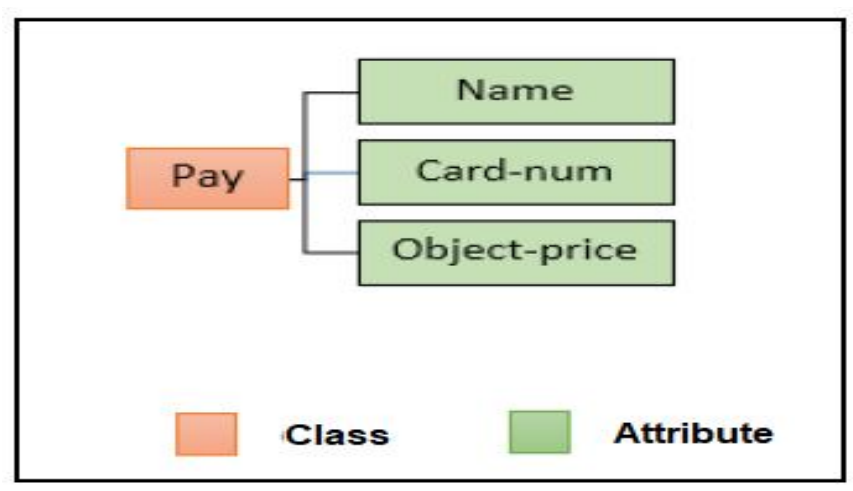

Figure 12: the Payment ontology hierarchy

\section{CONCLUSION}

Web services are the latest technology adopted for the integration and interoperability of distributed systems. They are characterized by their independence from platforms and operating systems, which has implied their adoption by the various commercial and industrial organizations offering their services through the Web, and consequently the increase in the number of services offered. 
The discovery of Web services constitutes an emerging research axis. Various approaches have been proposed. These approaches have moved from keyword based research (syntactic discovery) to semantic based methods. In this work, an agent-based approach for modeling semantics web services discovery is proposed.

Our approach of discovery of web services is based on standardized and powerful languages, and technologies (MARDS model, OWL-S Ontologies) therefore it can solve problems of the web services discovery in different application domains and at all levels of complexity. As part of a case study, we chose the Travel online problem to better explain, illustrate and help to understand proposed approach.

For the prospects, we are currently working on the implementation of our proposed approach.

\section{REFERENCES}

1. T. Berners-Lee, J. Hendler, O. Lassila, «The Semantic Web», In Scientific American, pages 35-43, May 2001. https://doi.org/10.1038/scientificamerican0501-34

2. E. Christensen, F. Curbera, G. Meredith, and S. Weerawarana. "Web services description language (wsdl) 1.1". pp 15, 17, 72,75 \& 77. http://www.w3.org/TR/wsdl, 2001.

3. T. Bellwood, L. Clement, D. Ehnebuske, A. Hately, M. Hondo, Y. L. Husband, K. Januszewski, S. Lee, B. McKee, J. Munter. "Uddi version 3.0. Published specification", Oasis, 2002. pp 16, 18, 23, 63 \& 72.

4. M. Gudgin, M. Hadley, N. Mendelsohn, J.-J. Moreau, and H. Frystyk Nielsen. "Simple Object Access Protocol (SOAP) Specification version 1.2", W3C Recommendation 27 April 2007. http ://www.w3.org/TR/soap12-part1/

5. B. Sajus, «La fonction Thésaurale au coeur des systèmes d'information», ADBS, avril 2002 www.adbs.fr/adbs/prodserv/jetude/html/prog110402a.html.

6. D. Martin, M. Burstein, J. Hobbs, O. Lassila, D. McDermott, S. McIlraith, S. Narayanan, M. Paolucci, B. Parsia, T. Payne, «OWL-S: Semantic markup for web services», Tech. rep., France Telecom, MINDL Maryland, NIST, Nokia, 2004.

7. B. Saravana Balaji, R.S. Rajkumar, I. Banar Fareed, "Service Profile based Ontological System for Selection and Ranking of Business Process Web Services",
International Journal of Advanced Trends in Computer Science and Engineering (IJATCSE), vol. 8, N. 1, pp. 18 $-22,2019$.

https://doi.org/10.30534/ijatcse/2019/04812019

8. K. Sivashanmugan, K. Verma, R. Mulye, Z. Zhong, A. Sheth, «SpeedR: Semantic Peerto-Peer Environment for Diverse Web Service Registries», http://webster.cs.uga.edu/ mulye/SemEnt/Speed-R.html, 2004.

9. Le-Hung $\mathrm{Vu}$, Manfred Hauswirth, Karl Aberer, «Towards P2P-Based Semantic Web services Discovery with QoS support », In Business Process Management Workshops, pages 18-31, 2005. lsirpeople.epfl.ch/ hauswirth/papers/-BPS2005.pdf https://doi.org/10.1007/11678564_3

10. B. Bounabat, «Méthode d'analyse et de conception orientée objet décisionnel. Application aux langages synchrones et aux systèmes répartis », doctoraldiss, Cadi Ayyad University, Faculty of sciences, Marrakech, Morocco, 2000.

11. M. Berrada, B. Bounabat, and M. Harti, "Modeling and simulation of Multi-Agent reactif decisionnal systems using business process management concepts", International Review on Computers and Software (IRECOS), vol. 2, n. 2, pp. 159-169, March 2007.

12. A. Aaroud, S. E. Labhalla, and B. Bounabat, "Modelling the handover function of global system for mobile communication", The International Journal of Modelling and Simulation, ACTA Press, vol 25, n. 2, 2005.

13. N. ADADI, M. BERRADA, M. HALIM and D. CHENOUNI, "Modeling and Implementation of Web Services Composition Based on MARDS", International Journal of Advanced Trends in Computer Science and Engineering (IJATCSE), vol. 8, N. 6, pp. 3381 - 3388, December 2019. https://doi.org/10.30534/ijatcse/2019/112862019

14. N. ADADI, M. BERRADA, M. HALIM and D. CHENOUNI, "Modeling and Formal Verification of Web Services Composition Using CADP", International Journal of Advanced Trends in Computer Science and Engineering (IJATCSE), vol. 8, N. 5, pp. 2339 - 2346, October 2019. https://doi.org/10.30534/ijatcse/2019/73852019 